\title{
A PATERNIDADE NA FRANÇA: entre igualização dos direitos parentais e lutas ligadas às relações sociais de sexo
}

\author{
Anne-Marie Devreux*
}

\begin{abstract}
Resumo: Na França, a evolução recente do Direito de Família e a redefinição dos direitos dos pais e das mães se desenvolveram em um contexto ideológico em que a noção de "novos pais" teve um papel importante, como em outras sociedades européias. O estudo das práticas masculinas na vida doméstica e da efetiva responsabilidade por filhas e filhos mostra, entretanto, um descompasso entre a idéia de que os pais teriam mudado e a realidade da divisão sexual do trabalho na família. Defendendo os direitos dos pais, em nome da "co-parentalidade", alguns homens, organizados em grupos de defesa dos pais divorciados, reivindicam direitos equivalentes entre pais e mães, invocando o "interesse da criança". O caráter reversível e intermitente do engajamento dos homens-pais na parentalidade e a prioridade que eles conferem à carreira profissional nos levam a interrogar o que está realmente em jogo em seus combates.
\end{abstract}

Palavras-chave: paternidade, parentalidade, relações sociais de sexo, trabalho parental, "novos pais", direito de família, direitos parentais.

A França se caracteriza, do ponto de vista demográfico, na Comunidade Européia e em relação a muitos países ditos desenvolvidos, por uma taxa de fecundidade relativamente

\footnotetext{
* Doutora em Sociologia, pesquisadora HDR (Habilitada a Dirigir Pesquisas), diretora do Laboratório Culturas e Sociedades Urbanas do Centro Nacional de Pesquisas Científicas (CNRS) e da Universidade Paris 8.

Tradução de Ana Liési Thurler do orginal em francês La paternité en France, entre égalisation des droits parentaux et luttes liées aux rapports sociaux de sexe, produzido para integrar este Dossiê.
}

Artigo recebido em 10 fev. 2006 e aprovado em 14 out. 2006. . 
"otimista" (1,9 filhos por mulher contra 1,5 no conjunto dos países da Comunidade Européia), por uma taxa de atividade feminina elevada (a despeito de políticas familiares tendendo a reduzir o número de mulheres no mercado de trabalho), por um número alto de divórcios (um em cada dois casamentos) e por um crescimento contínuo do número de famílias monoparentais, nas quais as mães se encontram sozinhas criando os filhos, resultando para elas a pauperização e a precarização social. As diretivas européias pressionam os Estadosmembros a instaurar a igualdade jurídica entre homens e mulheres, notadamente, entre pais e mães, impelindo-os a conciliar igualmente vida familiar e vida profissional.

Nesse contexto em permanente evolução, os homens se revelaram mais e mais ofensivos para obter, em nome da igualdade entre os sexos, uma igualdade de direitos parentais com as mães, sem zelar por instaurar uma igualdade de responsabilidades parentais com relação a suas filhas e filhos em suas práticas cotidianas. Veremos que, sob a noção de "interesse da criança" - lembrada sem cessar em todos os discursos da mídia, de autoridades políticas, de grupos de pressão - se oculta a busca de preservação de interesses masculinos.

Após apresentar as principais etapas da evolução do Direito de Família francês nos últimos trinta anos, o artigo vai expor os resultados mais significativos de um estudo da implicação prática dos homens nas responsabilidades parentais. Finalmente, estabelecerá uma ligação de tudo isso com as reivindicações masculinas, em matéria de compartilhamento dos direitos parentais.

\section{Transformações no quadro jurídico relativo às relações parentais e à parentalidade}

Depois de equiparar, em 1972, os direitos dos filhos ditos "naturais" - isto é, nascidos fora do casamento - aos direitos dos filhos ditos "legítimos" - isto é, nascidos de pais casados -, o Direito de Família francês não cessou de evoluir na busca de maior 
igualdade não somente entre os filhos, mas, sobretudo, entre os pais. Essa evolução jurídica acompanhou - mais do que precedeu - as práticas das francesas e dos franceses em matéria de casamento, de vida marital e mesmo de divórcio e da queda de vida um comum. $\mathrm{O}$ Direito francês pouco a pouco levou em conta a dissociação operada pelos casais entre estatuto matrimonial e o calendário de nascimento dos filhos. Assim, atualmente, em média, uma criança em duas nasce fora do casamento ( $45 \%$ dos nascimentos em 2004, contra $11 \%$ em 1980), em uma sociedade onde esses nascimentos não parecem "ilegítimos", uma vez que estão ocorrendo, de fato, dentro da ordem social e moral das coisas. Lemos todos os dias nos jornais anúncios de casamentos em que, para retomar a fórmula consagrada, filhos "têm a alegria de anunciar o casamento de seus pais". Muitas dessas crianças viverão a experiência da separação dos pais, pois $42 \%$ dos casamentos acabam em divórcio (contra 30\% há 20 anos). Assim, em torno de $17 \%$ dos filhos (de zero a 24 anos) vivem em uma família monoparental, das quais $86 \%$ compostas pela mãe "só" e seus filhos.

As modificações jurídicas mais recentes tendem a igualar os direitos do pai e da mãe, cuja assimetria vem de uma antiga disposição relativa aos nascimentos fora do casamento: no regime jurídico anterior à lei de $1^{\circ}$ de janeiro de 1993 , a autoridade parental - isto é, o direito e o dever de exercer atos de vigilância, de cuidado e de educação - sobre filhos nascidos fora do casamento era um direito da mãe, sendo que um compartilhamento dessa autoridade entre pai e mãe só era possível com a demanda apresentada conjuntamente por eles. Assim, até essa reforma, os pais casados tinham a autoridade parental sobre suas filhas e filhos comuns atribuída a uma e a outro, enquanto, entre casais coabitando sem casamento, o pai "natural", ainda que pudesse reconhecr seu filho no nascimento, e mesmo lhe dar o nome, não usufruia dessa autoridade jurídica sobre a criança. $\mathrm{Na}$ prática, ainda que não a demandassem junto ao Tribunal de instância de seu domicílio, pais não-casados agiam como co-responsáveis por seus filhos comuns, a maior parte do tempo. Nos casos de separação, o juiz orientava suas decisões concernentes ao direito de guarda se 
apoiando nas práticas anteriores do casal. Em 1993, essa disparidade de direitos entre pai e mãe sobre um filho nascido fora do casamento desapareceu, o que aproximou ainda mais filhos "naturais" dos filhos "legítimos".

Na prática, em caso de separação do casal parental - casado ou não - a guarda dos filhos mais freqüentemente ficava com a mãe, tendo o pai "direito de visita e permanência". Pouco a pouco a noção de mãe guardiã / pai guardião, que tornava a mãe ou o pai referência em matéria de domicílio da criança, foi substituída por "residência habitual" da criança, fazendo dela ponto central da questão da guarda. A filha ou filho de pais separados morava, mais freqüentemente, com a mãe, sendo que o pai exercia o direito de visita e, eventualmente, o de permanência durante parte das férias ou fim de semana.

Com a multiplicação das separações conjugais e com as mulheres se lançando ao trabalho assalariado, a despeito de políticas de família visando mantê-las em casa, a antiga percepção do casal tradicional formado por um "pai provedor" e por uma "mãe guardiã do lar e educadora dos filhos" se encontra mais e mais em evidente descompasso com as realidades vividas pelos casais parentais. Atualmente há um movimento de reivindicação paterna usando particularmente a tribuna mediática para difundir seus discursos, de modo a colocar seus problemas na esfera política. Em 2002, uma nova lei instituiu a residência alternada das crianças após a separação conjugal, acabando com a noção de genitor guardião, supondo que a criança residiria principalmente com um de seus pais e, mais ou menos regularmente, iria à casa do outro. Essa lei foi preparada por Comissão Parlamentar em longo trabalho que concedeu grande espaço às associações em defesa dos pais divorciados. Esses homens fizeram valer a suposição de que os pais se ocupavam tanto com suas crianças quanto as mães, como uma realidade advinda da "coparentalidade". Essa expressão figurou na exposição de motivos da lei, ao ser defendida pela Ministra da Família, na oportunidade, Ségolène Royal. Desde então, juízes com a responsabilidade de regular as conseqüências do divórcio ou da separação conjugal sobre a vida das crianças são intimados a encontrar uma solução que 
efetive a residência alternada para a criança - que passará a residir parte igual de tempo na casa do pai e na casa da mãe, independente do investimento parental que cada um deles fez durante a vida conjugal, anterior à separação. Para completar esse quadro da evolução recente do Direito da Família francês, observemos que, a partir de 2005, após décadas de resistência dos legisladores, o nome da mãe adquiriu um valor quase igual ao do pai. Com efeito, diferentemente de alguns vizinhos europeus, a França manteve até então o nome do pai como patronímico obrigatório da criança, não somente no quadro do casamento, mas, na prática, também na maior parte dos nascimentos fora do casamento. Para que a mãe pudesse dar seu (sobre)nome à criança, seria necessário que ela a reconhecesse com precedência ao pai, o que não era uma prática possível na oportunidade do nascimento - considerando suas limitações de mobilidade nessa ocasião. A mãe poderia reconhecê-la antes do nascimento, como aliás, também o pai. ${ }^{1}$ Nesse caso, entretanto, ela precisaria fazê-lo em segredo, sem avisar o pai, o que, evidentemente, traria conseqüências para o casal parental. Atualmente os pais podem decidir em comum acordo dar cada um seu nome ao filho, na ordem que preferirem. Em caso de desacordo, no entanto, continua a prevalecer o nome do pai.

Ao examinarmos tudo isso de uma perspectiva sociológica, constatamos a separação das idéias de "parental" e "parentalidade". Graças especialmente às análises feministas, os cuidados com os filhos, a criação e a educação deles não são nem um prosseguimento "natural", nem um seguimento "lógico" da gravidez e do parto, mas uma função social assumida quase exclusivamente pela mulher. Até então, em nossas sociedades, a paternidade era concebida como a versão "cultural" e intergeracional das atividades parentais, estabelecendo a filiação, inscrevendo filhas e filhos na sociedade e nas gerações. A maternidade era sua face "natural" e emocional, a tal ponto que, ignorando necessitar fazê-lo, boa parte das mães "esqueciam" de reconhecer sua filha ou filho após o nascimento. Do ponto de vista da sociedade, contava somente o reconhecimento paterno. A valorização social do nome da mãe, com a lei entrando em vigor em janeiro de 2005, provavelmente terá como efeito 
contrabalançar, pouco a pouco, o peso simbólico do "nome do pai" sobre o qual repousam as teorias psicanalíticas, tão difundidas na Europa ocidental. Os filhos e filhas estarão mais inscritos do que antes nas duas linhas parentais e escolherão, quando se tornarem pais, o nome que desejam transmitir a seus descendentes e, assim, o desaparecimento do nome das mulheres cessará. As representações sociais da maternidade e da paternidade, entretanto, desempenharão um papel na escolha do nome, ainda por longo tempo. Pesquisa sobre a construção parental (Combes e Devreux, 1991, 1994) mostra que as mulheres "escolhem" o nome do pai como patronímico para suas filhas e filhos, mesmo tendo a opção de adotar o seu próprio patronímico. O pretexto é, freqüentemente, que essa "vantagem" simbólica reequilibra os benefícios sociais da maternidade: são elas que carregam os filhos, portanto, é bom deixar algo positivo aos homens. Assim, as mulheres mesmas reproduzem a dicotomia maternidade-natural e paternidade-cultural.

Atualmente, a França vive o momento da "co-parentalidade". Após estabelecer a filiação de suas crianças conforme as novas regras e, portanto, sua "co-parentalidade", dá-se como suposto que pais e mães se ocupam igualmente de suas crianças. Na realidade, o que vem ocorrendo? As práticas masculinas e femininas ligadas à educação das crianças na família evoluíram no mesmo ritmo que os esquemas de pensamento e o quadro legislativo?

\section{Evolução da divisão sexual do trabalho parental}

Desde o início dos anos 80, a idéia de "novos pais" teve um sucesso crescente em inúmeros países ocidentais, a ponto de se tornar um conceito ordinário ao se falar em evolução das mentalidades masculinas. E essa idéia disseminou-se, com ligeiras diferenças no tempo entre um país e outro, em função de diferentes representações sociais ligadas aos papéis do pai e da mãe na educação dos filhos e, correlativamente, à legitimidade do trabalho profissional das mulheres e sua ausência de casa. 
No domínio das práticas familiares - como em todos os domínios - a evolução das práticas concretas não pode ser analisada separadamente das representações dominantes. Sublinhar esse imperativo metodológico para compreender a transformação social em matéria da divisão sexual do trabalho foi uma conquista das pesquisas feministas desenvolvidas nesses países. Modificações no quadro legal e mudanças nas mentalidades não são suficientes para instaurar uma nova ordem entre os sexos. A igualdade entre os sexos não pode ocorrer, de fato, sem uma evolução na divisão do trabalho e nas condições materiais nas quais ele se realiza. Nem a co-parentalidade pode ter o sentido de equivalência material e simbólica, diacrônica e sincrônica, como supõe o prefixo "co". Não sendo assim, a "co-parentalidade" não vai além de uma palavra de ordem, de um slogan "publicitário", destituído de suporte na realidade.

Um estudo do emprego do tempo pelas francesas e pelos franceses me permitiu abordar a questão da realidade da evolução das práticas masculinas na vida doméstica (Devreux e Frinking, 2001). De modo regular (todos os dez anos, aproximadamente), o INSEE produz pesquisa em âmbito nacional, na qual são levantadas todas as atividades, no decorrer de um dia, dos homens e das mulheres, a partir de 15 anos de idade. Sobre essa base, é possível estudar a forma como as atividades - profissionais, domésticas, parentais, associativas, lúdicas, etc... - são distribuídas não somente ao longo das horas do dia, mas também entre os membros da família, sem observá-las diretamente nas situações reais. Pode-se, assim, reconstituir as condições nas quais o trabalho doméstico - a limpeza, a lavagem de roupa, as compras, a gestão administrativa, a bricolagem, a jardinagem, etc. - e o trabalho parental - cuidar de uma criança, seguir seu trabalho escolar, assegurar seus deslocamentos, acompanhar suas brincadeiras, etc... - são efetuados por um indivíduo: durante quanto tempo para cada atividade, em presença de quem, quantas vezes no decorrer do dia, etc...

O trabalho doméstico e parental é um objeto clássico da sociologia das relações sociais de sexo, mas, até presentemente, não 
havia sido estudado, quantitativamente e em larga escala, a partir dos homens, a tal ponto sua presença (ou sua ausência) na família não colocava questões aos sociólogos. Em continuidade, com os primeiros trabalhos das ciências sociais sobre as mulheres, o trabalho doméstico parecia dever acentuar a esfera de atividades delas, ainda que os discursos dominantes fizessem, sem cessar, referências a uma "novidade", uma mudança nas práticas paternas. Eu quis, então, verificar de perto se havia, de fato, uma realidade material atrás dessa noção de "novos pais", atrás dessas imagens de publicidade que se propagaram nas paredes de nossas cidades e nas telas de nossos televisores, mostrando jovens pais empenhados, atenciosos junto a seus filhos, trocando fraldas, segurando uma mãozinha em um passeio, até mesmo ajudando a esposa na cozinha. Diante dessas imagens e construções ideológicas, o estudo do emprego do tempo apoiado em uma amostra representativa da população, poderia garantir uma certa objetivação das práticas.

Com a publicação dos primeiros resultados da pesquisa do INSEE, os franceses compreenderam que as coisas não evoluíram tanto assim nas famílias. A despeito de uma transformação profunda na sociedade francesa e do lugar que as mulheres ocupam nela particularmente no mercado de trabalho -, a parte assumida pelos homens no trabalho doméstico e parental pouco progrediu em vinte anos. Pior ainda. Parece que nos últimos trinta anos as mudanças mais importantes ocorreram na primeira década do período e a evolução da divisão do trabalho entre o casal, de algum modo se "comprimiu" em seguida. As mulheres continuam a realizar $2 / 3$ do trabalho doméstico e parental, ou seja, o dobro da parte assumida pelos homens que - "novos pais" ou não -, depois de dez anos, só reservam a essas atividades mais dez minutos por dia. Assim, as mulheres consagram em torno de 30 horas semanais aos cuidados da casa e dos filhos, enquanto os homens consagram em torno de 15 horas.

Na pesquisa apareceu claramente, sobretudo, que a chegada de um primeiro filho modifica essa divisão já desigual. Se nos casais sem filhos os homens participam com $37 \%$ do trabalho na família, 
quando um filho chega, essa participação cai para 34\%. Depois do segundo filho, se os pais consagram um pouco mais de tempo aos cuidados diretos com os filhos (20 minutos suplementares em toda a semana, ou seja, menos de três minutos por dia, com a chegada do segundo filho), eles reduzem o tempo concedido ao trabalho doméstico. O terceiro filho agrava essa regressão.

Se deixarmos de considerar o indicador tempo investido, e considerarmos o número efetivo de pais se responsabilizando por uma parte do trabalho doméstico e parental constatamos que, nas famílias com dois ou três filhos, três pais em cada quatro se abstêm totalmente de qualquer participação. O fenômeno dos "novos pais" só pode dizer respeito a um pai em cada quatro.

Constamos que, conforme a família cresce, os homens se dedicam menos e menos a atividades como a limpeza da cozinha, da louça e da casa e a lavagem da roupa, excetuando-se a bricolagem e a jardinagem. No domínio parental, a presença de um segundo filho leva os pais a se consagrarem um pouco mais aos cuidados corporais, aos jogos ou ao transporte dos filhos, mas a chegada de um terceiro filho leva a um recuo da participação dos pais.

Se esses fatos parecem marginais, eles indicam um desengajamento de um número significativo de pais em relação aos cuidados com as crianças. Considerando a constituição dos dados das pesquisas sobre Emprego do tempo, o fato de três em cada quatro pais não terem realizado qualquer tarefa diretamente ligada aos filhos, significa que eles não passaram sequer dez minutos por dia junto aos filhos.

O caráter inconstante, e até mesmo reversível, do investimento paterno é confirmado por uma pesquisa sobre a utilização da licença parental pelos pais suecos. O estudo mostra que eles são tentados a deixar de trabalhar alguns meses na chegada de um primeiro filho (entretanto, fazem-no 10 a 13 vezes menos do que as mães suecas), mas, feita a experiência, eles não a repetem com um segundo ou terceiro filho. Conforme testemunho deles, sendo o benefício pessoal de tal experiência afetiva conquistado por eles mesmos, o 
“interesse da criança” não constitui argumento suficientemente forte para sensibilizá-los a renová-la (Brachet, 2004).

A análise das situações de monoparentalidade por meio das pesquisas sobre Emprego do tempo revela que os homens declarando viver sós com um ou mais filhos não sofrem as mesmas pressões que as mulheres em situação semelhante. Com efeito, somente um em cada dez pais responsáveis pelos filhos os cuidou. Menos da metade desses homens prepararam uma refeição ao dia. O total deles consagrou ao trabalho doméstico e parental pouco mais da metade do tempo que a ele consagraram as mulheres sós, com filhos. Em compensação, eles tiveram mais tempo de lazer e de disponibilidade para cuidar de suas relações sociais. Isso nos leva a interrogar sobre a divisão do trabalho entre pai e mãe após a separação conjugal, à medida que uma criança tem as mesmas necessidades, seja vivendo com os dois ou alternadamente com ele e com ela: ser alimentada, ser vestida, acompanhada em seus jogos, à escola.

Considerando a idade das crianças, observamos um aumento médio da duração do trabalho parental dedicado pelos homens franceses aos filhos com menos de 3 anos, passando de 3 horas e meia por semana, em 1974, para 5 horas e 20 minutos em 1986 e 6 horas e 10 minutos em 1999. As francesas, mães de crianças até 3 anos - idade da entrada na escola maternal - lhes consagram três vezes mais tempo, ontem como hoje. É verdade que essa duração inclui o tempo da guarda cotidiana das crianças, compreendendo aí, o tempo na casa das mães que deixaram de trabalhar. Em 1999, um em cada três pais de crianças nessa faixa etária estava totalmente fora desse campo de atividades, deixando à mãe - qualquer que fosse o perfil socioprofissional dela - a preocupação de assegurar a permanência da presença parental.

Assim, no que concerne à atividade de "guardar" uma criança, isto é, de vigilância para garantir sua segurança, 97\% das mães de crianças pequenas que exercem uma atividade profissional declararam ter realizado essa tarefa ao menos uma vez ao dia, contra $51 \%$ dos pais nessas circunstâncias. Quando os homens precisam se 
ocupar com os filhos, preferem outras tarefas mais valorizadas: sair ou jogar com eles.

Podemos dizer que, se a "nova paternidade" existe, ela é representada pelos pais de um primeiro filho pequeno, isto é, por homens que se tornaram pais recentemente. Mais do que uma mudança de fundo, essa "nova paternidade" se refere a homens que se tornaram pais recentemente e que, com o crescimento da criança ou com a chegada do segundo filho, retornarão ao modelo tradicional de divisão de tarefas com a mãe.

Muitas pesquisas francesas mostraram que, de um modo geral, ter filhos favorece a carreira profissional dos pais, enquanto freia a carreira das mães (Devreux, 1984; Ferrand, 1984; Fermanian e Lagarde, 1998; Gadéa e Marry, 2000). Fermanian e Lagarde observaram um superinvestimento dos homens-pais no trabalho profissional: um pai assalariado com um filho exerce sua atividade profissional com, em média, em torno de meia hora a mais por semana do que um homem casado sem filhos. Um pai com dois filhos trabalha em torno de uma hora a mais, e um pai com três filhos ou mais consagra em torno de duas horas suplementares à carreira.

Uma política implementada para favorecer a conciliação entre vida profissional e vida familiar com a instauração de um abono família de educação para indenizar pais que lançam mão de uma licença parental para cuidar de um filho com menos de 3 anos de idade, teve como efeito retirar boa parte das mães do mercado de trabalho. Assim, hoje, na França, a taxa de atividade das mães com 2 filhos (entre eles um com menos de 3 anos) regrediu 15\% desde que essa política familiar foi implantada - inicialmente aberta a pais e mães com um só filho e, depois, ampliada para pais e mães com 2 e 3 filhos.

Do ponto de vista das práticas concretas, a noção de "novos pais" surge como pura construção ideológica, desligada das realidades da vida familiar e da divisão do trabalho entre os sexos. Isso não significa que as mentalidades dos homens não mudaram. De um lado, crianças privadas do reconhecimento paterno são raras 
hoje, o que está ligado a mudanças no sentido dos nascimentos fora do casamento. Desse ponto de vista, a paternidade jurídica mudou radicalmente. De outro lado, os pais franceses não se vêem mais como pater familias, autoritários, distantes da família, estranhos a seu cotidiano, mas eles fazem uma seleção entre as atividades necessárias à criança, camuflando o fato de que as mulheres continuam a assegurar a maior parte dessas atividades, especialmente a "guarda" diária das crianças. Se a relação co-parental (isto é, o estabelecimento de uma dupla filiação para a maioria das crianças) tornou-se a norma, a co-parentalidade ainda está nos espíritos, não nos fatos.

\section{Parentalidade e lutas de sexos: do uso masculino dos paradoxos da igualdade}

Relativamente a outras sociedades, a sociedade francesa pode parecer um espaço com maior igualdade entre homens e mulheres e maior eqüidade na divisão sexual do trabalho na família. De fato, a participação dos homens nas reponsabilidades cotidianas relativas às crianças está longe de ser considerada referência, em muitas regiões do planeta. A situação francesa pode parecer de tal modo favorável às mulheres que discutir o sentido preciso dessa "coparentalidade" imperfeita pode parecer completamente secundário.

Do ponto de vista da análise das relações sociais de sexo que aqui nos preocupa, os fatos sociais desenvolvidos neste artigo ilustram como, mesmo em sociedades em que a igualdade entre os sexos parece estar em bom caminho, essas relações sociais se redefinem sem cessar pelo jogo das lutas de resistência: não somente as lutas travadas pelas mulheres, individual ou coletivamente, para mitigar as desigualdades de sexo que ainda sofrem e para redefinir seu lugar na divisão sexual do trabalho, mas também - e este é, freqüentemente, um ponto ocultado nas análises de gênero - as resistências individuais e coletivas em que os homens se empenham para preservar os privilégios que adquiriram com a dominação masculina. 
No debate francês sobre a divisão dos direitos parentais após o divórcio ou a separação do casal, a noção de "co-parentalidade" surgiu como o pivô em torno do qual giram as argumentações em favor de uma estrita igualdade de direitos dos pais com as mães. Trata-se da eficácia da ideologia ligada ao slogan "novos pais" que entrou em ação nesses debates: visto ter se suposto que os pais haviam modificado suas práticas e investido em assumir encargos junto a suas crianças, seria necessário, então, falar em parentalidade partilhada com as mães, ou seja, em "co-parentalidade", a parentalidade assumida conjuntamente. A partir daí, tornar-se-ia necessário, em nome da justiça, alinhar os direitos paternos a todos os direitos parentais ainda reservados às mães, como o "benefício" da guarda das crianças após o divórcio.

Diversamente da "parentalidade" - que evoca o laço concreto, cotidiano, entre um pai e/ou uma mãe e uma criança -, a "coparentalidade" define a parentalidade primeiro em relação ao outro (pai ou mãe). Ela pertence, assim, à mesma lógica retórica da noção de "direitos parentais", dissociada de deveres parentais ou da noção de autoridade parental separada da responsabilidade parental. Sob o manto da igualdade, a co-parentalidade fala das relações "políticas" entre os pais e as mães, mais do que sobre a realidade de assumir encargos concretos junto às crianças.

Nos debates sobre os fundamentos da divisão da autoridade parental ou da guarda da crianças após o divórcio (ou da separação) que, recentemente, se disseminou na sociedade francesa-, assistimos, por um lado, ao empoderamento da noção de "direitos do pai" com sua tradução jurídica em termos de igualdade dos direitos entre os pais (com o ocultamento do fato de que se trata de uma reivindicação de direitos sobre a criança) e, por outro lado, a uma resistência dos homens em assumir encargos relativos às necessidades cotidianas das crianças. E a divisão tradicional do trabalho entre os sexos, que torna os homens indisponíveis a assumir esses encargos, por sua função de provedores, modificou-se profundamente com a presença das mães no mercado de trabalho. 
Nas argumentações em favor de uma divisão dos direitos parentais, a noção de "interesse da criança" é regularmente empregada. Não é somente em nome da eqüidade entre os sexos, mas também em nome do interesse da criança que as associações de pais divorciados reivindicam direitos iguais para pais e mães. Mas qual é a resposta às necessidades da criança, resumida em "interesse da criança", se não for, além de seu sustento, alimentação e educação, a tranqüilidade e a qualidade de sua vida? Essa tranqüilidade e essa qualidade de vida estão no cerne do dever parental. "Guardar" uma criança é a modalidade material, física e moral dessa atribuição. Guardá-la de todo perigo, enquanto ela for imatura e dependente é garantir-lhe as condições de vida e de sobrevivência. Exercer a parentalidade é, antes de tudo, aperfeiçoar a reprodução da vida humana. Ora, nessa tarefa que é o fundamento da reprodução da sociedade, verificamos que, ainda hoje, são as mães quem asseguram a maior parte do sustento e da qualidade de vida às crianças - de três quartos à totalidade, conforme os meios socioprofissionais -, são as mães quem garantem sua "guarda" propriamente, permitindo seu desenvolvimento físico e intelectual.

Se é verdade que o domínio do desenvolvimento intelectual parece reter mais o interesse dos pais que consagram o tempo que passam junto a seus filhos, preferencialmente, a jogos, a trabalho escolar ou a passeios, com isso a divisão sexual do trabalho não muda nem de estrutura, nem de significação social, pois enquanto os homens não investem em um domínio de atividade, ela não adquire nem visibilidade, nem reconhecimento social. Por isso, o tempo de "guarda" ordinária, cotidiana de uma criança permanece sem valor social. As mulheres das classes superiores compreendem bem isso quando delegam - aliás, elas e seus cônjuges - essa tarefa a mulheres de camadas sociais inferiores, a quem elas - e eles - pagam como pessoal de serviço.

A análise do emprego do tempo das francesas e dos franceses mostra que os homens continuam a selecionar as tarefas que não entram em contradição com outros domínios de suas atividades: trabalho profissional, lazer ou relações sociais. Eles não se tornam 
atualmente mais disponíveis que antigamente a tarefas que poderiam contrariar suas atividades habituais, salvo exceções, em certas categorias sociais. Ora, essas exceções - que concernem a homens de camadas médias urbanas e intelectuais - são, sistematicamente, colocadas em destaque e, nos discursos, estendidas ao conjunto dos pais. A partir desses casos, estatisticamente minoritários e socialmente bem localizados, tarefas efetuadas de tempos em tempos e por um pequeno número de pais são valorizadas e enobrecidas, enquanto tarefas ordinariamente assumidas pelas mães são mantidas na invisibilidade e desvalorizadas.

Sob a reivindicação masculina à igualdade de direitos entre pais e mães se encontra a denúncia de um poder que as mães teriam sobre suas crianças por sua proximidade cotidiana, pela presença permanente a seu lado. $\mathrm{O}$ tema do poder das mulheres emergiu a partir do momento em que as feministas contestaram a dominação masculina. Revertendo o argumento, os grupos masculinos de pressão, sustentados às vezes por sociólogos, colocaram um cena o poder das mulheres na família: poder ligado à gestão da vida cotidiana, ao savoir-faire doméstico, à onipotência da maternidade desde que as mulheres obtiveram o direito à contracepção e ao aborto. As noções de "contrato entre os sexos" ou, ainda, de "negociação conjugal" que embelezam a sociologia contemporânea da família na França se apoiam em uma visão das relações homens-mulheres onde uns e outras deteriam "capitais", isto é, recursos econômicos, sociais, políticos, se não com o mesmo peso, ao menos da mesma natureza. Regateios entre cônjuges na vida conjugal colocariam frente a frente duas liberdades, duas "individualidades" diferentes mas homólogas do ponto de vista do poder. Por exemplo, sociólogos franceses opuseram o poder das mulheres na realização das tarefas culinárias (Glaude e de Singly, 1986) ou de cuidados com a roupa (Kaufmann, 1992) e o poder dos homens na esfera profissional e política.

Trata-se do ocultamento da dessimetria entre os sexos que permite retornar à questão da igualdade e utilizar os paradoxos aparentes das relações sociais de sexo. Com efeito, como justificar a 
manutenção de uma desigualdade de direitos entre pais dos dois sexos em nome de uma desigual repartição dos encargos parentais efetivos, quando é dado como suposto que todas as instâncias da sociedade buscam a paridade? Como as mulheres poderiam reivindicar direitos diferentes para cada sexo, elas que colocaram em cena a palavra de ordem, igualdade entre homens e mulheres?

Assumindo a palavra das mulheres e de feministas, certos homens, em particular os grupos de defesa dos pais separados, jogam com esse paradoxo para obter direitos que mantêm as desigualdades de fato e reproduzem a estrutura assimétrica da divisão sexual do trabalho. Podemos dizer que, para além da questão do "interesse da criança", esses debates franceses tratam, sobretudo, da preservação dos interesses dos homens (McMahon, 1999) e dos dividendos do patriarcado (Connell, 2000). Novos pais ou não, os homens continuam a escolher em que momento e em que condições eles se ocupam com suas crianças, assumindo, de fato, parcialmente suas responsabilidades parentais diante do conjunto da sociedade e demandando a ela reconhecimento de prerrogativas iguais às das mulheres que não fazem escolhas: quaisquer que sejam as condições, o cuidado com as crianças lhes incumbe, tenham elas ou não outros campos de atividade.

\section{Nota}

1 O reconhecimento antes do nascimento é prática freqüente na França, sendo mesmo acompanhada estatisticamente pelo Instituto Nacional de Estatísticas e Estudos Econômicos (INSEE), instituição correspondente ao IBGE, no Brasil (N. da T.). 
La paternité en France, entre égalisation des droits parentaux et luttes liées aux rapports sociaux de sexe

Résumé: En France, l'évolution récente du droit de la famille et la redéfinition des droits des pères et des mères se sont déroulées dans un contexte idéologique où la notion de "nouveaux pères" a joué un rôle majeur tout comme dans d'autres sociétés européennes. L'étude des pratiques masculines dans la vie domestique et de la prise en charge effective des enfants montre cependant un décalage entre l'idée que les pères ont changé et la réalité de la division sexuelle du travail dans la famille. Défendant les droits des pères au nom de la “ co-parentalité “, certains hommes, organisés dans des groupes de défense des pères divorcés, revendiquent des droits équivalents entre pères et mères en faisant valoir " l'intérêt de l'enfant ". Mais le caractère réversible de l'engagement des pères dans la parentalité et la priorité qu'ils donnent à leur carrière professionnelle font s'interroger sur l'enjeu réel de leurs combats.

Mots-clés: paternité, parentalité, rapports sociaux de sexe, travail parental, "nouveaux pères", droit de la famille, droits parentaux.

\section{Referências bilbiográficas}

BRACHET, Sara. L'égalité: une vaine quête? Hommes, femmes et congé parental en Suède. Terrain, n. 42, p. 65-80, 2004.

COMBES, Danièle; DEVREUX, Anne-Marie. Construire sa parenté: reconnaissance, légitimation, dénomination des enfants. Paris: CNRS, 1991. (Collection CSU).

COMBES, Danièle; DEVREUX, Anne-Marie. Les droits et les devoirs parentaux ou l'appropriation des enfants. Recherches féministes, v. 7, n. 1, p. 43-58, 1994.

CONNELL, Robert W. The men and the boys. Cambridge: Polity, 2000.

DEVREUX, Anne-Marie. A teoria das relações sociais de sexo: um quadro de análise sobre a dominação masculina. Sociedade e Estado, v. 20, n. 3, set./dez. 2005.

. La parentalité dans le travail: rôles de sexe et rapports sociaux. In: BARRÈRE-MAURISSON, M. A. et al. Le sexe $d u$ 
travail: structures familiales et système productif. Grenoble: Presses Universitaires de Grenoble, 1984.

DEVREUX, Anne-Marie; FRINKING, Gerard. Les pratiques des hommes dans le travail domestique: une comparaison franco-néerlandaise. Paris: CSU-CNRS, DARES Ministère de l'Emploi et de la Solidarité; Tilburg: WORC-Tilburg University, 2001.

FERMANIAN, Jean-David; LAGARDE, Sylvie. Les horaires de travail dans le couple. Economie et Statistique, n. 321-322, p. 89-110, 1998.

FERRAND, Michèle. Paternité et vie professionnelle. In: BARRÈREMAURISSON, M. A. et al. Le sexe du travail: structures familiales et système productif. Grenoble: Presses Universitaires de Grenoble, 1984.

GADEA, Charles; MARRY, Catherine. Les pères qui gagnent: descendance et réussite professionnelle chez les ingénieurs. Travail, genre et sociétés, n. 3, 2000.

GLAUDE, Michel; SINGLY, François de. L'organisation domestique: pouvoir et négociation. Economie et Statistique, n. 187, p. 3-30, 1986.

KAUFMANN, Jean-Claude. La trame conjugale: analyse du couple par son linge. Paris: Nathan, Agora, 1992.

McMAHON Anthony. Taking care of men: sexual politics in the public mind. Cambridge University Press, 1999. 